\title{
Profil trikomoniasis di Poliklinik Kulit dan Kelamin RSUP Prof. Dr. R. D. Kandou Manado periode 1 Januari 2011 - 31 Desember 2015
}

\author{
${ }^{1}$ Nurrahmi Alfari \\ ${ }^{2}$ Marlyn G. Kapantow \\ ${ }^{2}$ Thigita Pandaleke
}

\author{
${ }^{1}$ Kandidat Skripsi Fakultas Kedokteran Universitas Sam Ratulangi Manado \\ ${ }^{2}$ Bagian Ilmu Kesehatan Kulit dan Kelamin Fakultas Kedokteran \\ Universitas Sam Ratulangi Manado \\ Email: sarialfari@gmail.com
}

\begin{abstract}
According to WHO in 2008, prevalence of Trichomoniasis is number one of the total number of new cases of sexually transmitted diseases, reaching 276.4 million (Chlamydia trachomatis 105.7 million, 106.1 million Neisseria gonorrhea, syphilis 10.6 million). Trichomoniasis is a protozoal disease that attacks the lower urogenital tract in both men and women and is caused by Trichomonas vaginalis, this disease is usually transmitted through sexual intercourse. In women this parasitic infection mainly causes vaginitis, whereas in men can lead to urethritis but often asymptomatic so men rarely to do the check. This study's goal to gain trichomoniasis patients profile at the dermatovenereology clinic of Prof. Dr. R. D. Kandou General Hospital Manado during the period from January 2011 December 2015. This is a retrospective descriptive study from the secondary data of trichomoniasis patients based on age, type of job, complaints and clinical findings, and coinfection with other STDs. The results showed of 22 cases with trichomoniasis, found most often in the age group 25-44 years as many as 15 cases $(68.18 \%)$, with the youngest 16 and the oldest 41 years of age, most of the patients are housewife (45.45\%), complaints vary but all come with complaints vaginal discharge, co-infected with other STDs, 7 cases (31.82\%).
\end{abstract}

Keywords: trichomoniasis, trichomonas vaginalis, STD

\begin{abstract}
Abstrak: Trikomoniasis menempati nomor urut pertama prevalensinya menurut World health Organization pada tahun 2008 yakni mencapai 276,4 juta dari jumlah total kasus baru penyakit menular seksual(105.7 juta Klamidia trakomatis, 106.1 juta Neisseria gonore, 10.6 juta sifilis). Trikomoniasis merupakan suatu penyakit infeksi protozoa yang menyerang traktus urogenitalis bagian bawah baik pada pria maupun wanita dan disebabkan oleh Trichomonas vaginalis, biasanya penyakit ini ditularkan melalui hubungan seksual. Pada wanita infeksi parasit ini terutama menyebabkan vaginitis, sedangkan pada laki-laki menyebabkan uretritis namun sering asimptomatik sehingga pria jarang memeriksakan diri. Tujuan penelitian ini untuk mengetahui profil pasien trikomoniasis di poliklinik kulit dan kelamin RSUP Prof. Dr. R. D. Kandou Manado Periode Januari 2011 - Desember 2015. Penelitian ini merupakan penelitian deskriptif retrospektif dari data sekuduer pasien trikomoniasis berdasarkan umur, jenis Pekerjaan, keluhan dan temuan klinis dan ko-infeksi dengan IMS lainnya. Hasil penelitian menunjukkan dari 22 kasus dengan trikomoniasis, didapatkan paling sering pada kelompok usia 25-44 tahun sebesar 15 kasus $(68,18 \%)$, dengan usia termuda 16 tahun dan usia tertua 41 tahun., pekerjaan terbanyak Ibu Rumah Tangga $(45,45 \%)$, keluhan beragam namun seluruhnya datang dengan keluhan duh tubuh, ko-infeksi IMS lainnya 7 kasus $(31,82 \%)$.
\end{abstract}

Kata kunci: trikomoniasis, trikomonas vaginalis, IMS 
Trikomoniasis merupakan suatu penyakit infeksi protozoa yang menyerang traktus urogenitalis bagian bawah baik pada pria maupun wanita dan disebabkan oleh Trichomonas vaginalis, biasanya penyakit ini ditularkan melalui hubungan seksual. ${ }^{1}$ Pada pria umumnya asimtomatik dan prevalensinya lebih rendah dibandingkan pada wanita. ${ }^{2}$ Keadaan dimana lingkungan kurang baik dapat terjadi infeksi secara tidak langsung melalui alat mandi seperti lap mandi, handuk atau alat sanitasi seperti toilet seat. ${ }^{3}$

Menurut World Heath Organization, prevalensi trikomoniasis pada tahun 2008 mencapai 276,4 juta dari jumlah total kasus baru penyakit menular seksual (105.7 juta Klamidia trakomatis, 106.1 juta Neisseria gonore, 10.6 juta sifilis). ${ }^{4}$ Trikomoniasis telah dikaitkan dengan peningkatan serokonversi virus HIV pada perempuan. ${ }^{5}$ Selain itu, trikomoniasis dikaitkan dengan kelahiran prematur atau pecahnya ketuban dan berat badan lahir rendah. ${ }^{6}$ Faktor resiko trikomoniasis diantaranya penyakit menular seksual lainnya, kontak seksual dengan banyak pasangan seksual, tidak pakai kondom, pekerja seks komersial, dan kadar $\mathrm{pH}$ vagina yang tinggi. ${ }^{7}$ Penelitian yang dilakukan di daerah Bitung dengan subjek penelitian Wanita Penjaja seks, didapatkan pada tahun 2003 WPS jalanan sebesar $20 \%$ dan WPS tempat hiburan $16 \%$ terinfeksi trikomoniasis. $^{8}$

Pada HIV postif, ini akan meningkatkan shedding virus pada saluran reproduksi, sehingga daya tular HIV meningkat. Pada HIV negatif, IMS golongan ini meningkatkan konsentrasi sel target infeksi HIV (limfosit CD4) pada endoserviks sehingga meningkatkan kerentanan akan infeksi HIV. ${ }^{9}$ Siklus hidup trikomonas vaginalis yaitu bentuk tropozoit ditularkan melalui hubungan seksual dan tidak ada bentuk kista. Pada kondisi optimum inti membelah secara mitosis setiap 8 sampai 12 jam. Hal ini menyebabkan jumlah trikomonas vaginalis sangat banyak pada permukaan mukosa dan lumen saluran urogenital bagian bawah, diperkirakan bisa terdapat $10^{1}-10^{5}$ protozoa/mL cairan vagina. ${ }^{7}$

Diagnosis trikomoniasis biasanya didasarkan pada pemeriksaan mikroskopis langsung dan kultur. Pemeriksaan mikroskopis murah dan cepat, tapi sensitivitasnya rendah (50-70\%) spesifisitas $(100 \%)$ dan sangat tergantung pada pengalaman operator dan viabilitas protozoa. $^{10,11}$ Trikomoniasis ini bisa menjadi tanda perilaku seksual beresiko tinggi, dan prevalensinya yang tinggi pada banyak populasi menandakan dibutuhkannya konseling dan perubahan perilaku untuk mengurangi resiko pasien terjangkit penyakit menular seksual lainnya termasuk HIV/AIDS., ${ }^{71}$

Berdasarkan uraian diatas, penulis merasa tertarik untuk melakukan penelitian tentang profil trikomoniasis di RSUP Prof. Dr. R. D. Kandou Manado periode 1 Januari 2011 - 31 Desember 2015.

\section{METODE PENELITIAN}

Penelitian ini dilakukan secara retrospektifdeskriptif dengan mengambil data dari catatan rekam medik pasien di Instalasi Rekam Medik dan Buku register di Poliklinik Kulit dan Kelamin RSUP. Prof. Dr. R. D. Kandou Manado.Populasi dari penelitian ini adalah semua pasien baru yang datang di poliklinik Kulit dan Kelamin RSUP. Prof. Dr. R. D. Kandou Manado, Sampel adalah semua pasien baru yang terdiagnosis trikomoniaisi periode 2011-2015.

Dari catatan medik pasien yang dicatat meliputi jumlah kunjungan, umur, pekerjaan, keluhan dan temuan klinis, koinfeksi dengan IMS lainnya. Data yang sudah terkumpul diolah secara manual dan disusun menggunakan laptop, kemudian disajikan dalam bentuk tabel dan dianalisis berdasarkan hasil presentase.

\section{HASIL PENELITIAN}

Berdasarkan penelitian yang dilakukan di Poliklinik Kulit dan Kelamin RSUP. Prof. Dr. R. D. Kandou Manado Tahun 2011-2015 didapatkan jumlah keseluruhan 
pasien trikomoniasis sebanyak 22 kasus dengan hasil sebagai berikut:

Tabel 1. Distribusi pasien Trikomoniasis di Divisi Infeksi Menular seksual

\begin{tabular}{rccc}
\hline Tahun & $\begin{array}{c}\text { Total } \\
\text { Kunjungan } \\
\text { Divisi } \\
\text { Infeksi } \\
\text { Menular } \\
\text { Seksual }\end{array}$ & $\begin{array}{c}\text { Total } \\
\text { Kunjungan } \\
\text { Trikomoniasis }\end{array}$ \\
\hline 2011 & 132 & 2 & $0,29 \%$ \\
2012 & 73 & 0 & 0 \\
2013 & 196 & 6 & 0,86 \\
2014 & 135 & 10 & 1,44 \\
2015 & 159 & 4 & 0,58 \\
Jumlah & 695 & 22 & 3,17 \\
\hline
\end{tabular}

Distribusi kasus trikomoniasis sebesar 22 kasus baru $(3,17 \%)$ dari 695 kasus penyakit kelamin di Divisi Infeksi Menular Seksual seksual tahun 2011-2015.

Tabel 2. Distribusi kasus trikomoniasis berdasarkan umur

\begin{tabular}{ccc}
\hline Umur & $\begin{array}{c}\text { Jumlah kasus } \\
(\mathbf{n})\end{array}$ & $\mathbf{\%}$ \\
\hline $15-24$ & 7 & 31,82 \\
$25-44$ & 15 & 68,18 \\
$45-64$ & 0 & 0 \\
$\geq 65$ & 0 & 0 \\
Total & 22 & 100 \\
\hline
\end{tabular}

Distribusi kasus trikomoniasis berdasarkan usia terbanyak pada kelompok usia 25-44 tahun sebanyak 15 kasus $(68,18 \%), 15-24$ tahun sebanyak 7 kasus $(31,82 \%)$.

Tabel 3. Distribusi Kasus Trikomoniais Berdasarkan Jenis Pekerjaan

\begin{tabular}{ccc}
\hline $\begin{array}{c}\text { Jenis } \\
\text { Pekerjaan }\end{array}$ & Jumlah Kasus (n) & \% \\
\hline Ibu Rumah & 10 & 45,45 \\
Tangga & & \\
Pegawai & 4 & 18,18 \\
Negeri & & \\
Pelajar & 6 & 27,27 \\
Wiraswasta & 2 & 9,10 \\
Total & 22 & 100 \\
\hline
\end{tabular}

Distribusi kasus terbanyak ada pada Ibu Rumah Tangga sebanyak 10 kaus $(35,35 \%)$, Pelajar sebanyak 6 kasus $(27,27 \%)$.

Tabel 4. Distribusi Kasus Trikomoniasis menurut Keluhan

\begin{tabular}{ccc}
\hline Keluhan & $\begin{array}{c}\text { Jumlah } \\
\text { kasus (n) }\end{array}$ & \% \\
\hline Duh Tubuh & 22 & 100 \\
Gatal & 8 & 36,36 \\
Dispareunia & 2 & 9,09 \\
Disuria & 1 & 4,55 \\
Tak enak & 0 & 0 \\
perut bawah & & \\
Bau & 13 & 59,09 \\
\hline
\end{tabular}

Semua pasien trikomoniasis yang datang memeriksakan diri di Poliklinik Kulit dan Kelamin memiliki keluhan duh tubuh atau keputihan yang keluar dari vaginanya $(100 \%)$.

Tabel 5. Distribusi Kasus Trikomoniasis berdasarkan Temuan Klinis

\begin{tabular}{|c|c|c|}
\hline Temuan Klinis & $\begin{array}{c}\text { Jumlah } \\
\text { kasus (n) }\end{array}$ & $\%$ \\
\hline Eritema Vulva & 1 & 4,55 \\
\hline $\begin{array}{c}\text { Duh Tubuh } \\
\text { Kuning } \\
\text { Berbusa }\end{array}$ & 4 & 18,18 \\
\hline $\begin{array}{c}\text { Eritema } \\
\text { dinding Vagina } \\
\text { Duh Tubuh }\end{array}$ & 6 & 27,27 \\
\hline $\begin{array}{c}\text { Kuning } \\
\text { Berbusa+ } \\
\text { Eritema } \\
\text { dinding Vagina }\end{array}$ & 1 & 4,55 \\
\hline $\begin{array}{l}\text { Eritema Vulva } \\
\text { + Duh Tubuh }\end{array}$ & & \\
\hline $\begin{array}{c}\text { Kuning } \\
\text { Berbusa+ } \\
\text { Eritema } \\
\text { dinding Vagina }\end{array}$ & 2 & 9,09 \\
\hline $\begin{array}{l}\text { Strawberry } \\
\text { Cervix }\end{array}$ & 0 & 0 \\
\hline $\begin{array}{c}\text { Tanpa Temuan } \\
\text { Klinis }\end{array}$ & 8 & 36,36 \\
\hline Total & 22 & 100 \\
\hline
\end{tabular}


Distribusi trikomoniasis berdasarkan temuan klinis didapatkan eritema dinding vagina sebesar 6 kasus $(27,27 \%)$, kemudian diikuti dengan duh tubuh kuning berbusa sebesar 4 kasus $(18,18 \%)$, dan tidak didapatkan strawberry cervix sedangkan tanpa keluhan klinis sebesar 8 kasus $(36,36 \%)$.

Tabel.6.Distribusi Trikomoniasis koinfeksi dengan IMS lainnya

\begin{tabular}{ccc}
\hline $\begin{array}{c}\text { Trikomoniasis + IMS } \\
\text { lainnya }\end{array}$ & $\begin{array}{c}\text { Jumlah } \\
\text { kasus (n) }\end{array}$ & $\%$ \\
\hline $\begin{array}{c}\text { Trikomoniasis + } \\
\text { Bakterial Vaginosis } \\
\text { Trikomoniasis + } \\
\text { Kandidiasis }\end{array}$ & 3 & 13,63 \\
$\quad$ Vulvovaginalis & 2 & 9,09 \\
Trikomoniasis + & 1 & 4,55 \\
$\begin{array}{c}\text { Kondiloma Akuminata } \\
\text { Trikomoniasis + Ulkus }\end{array}$ & 1 & 4,55 \\
$\quad$ Mole & 15 & 68,18 \\
Tanpa IMS lainnya & 100 \\
Total & 22 & 100 \\
\hline
\end{tabular}

Distribusi kasus trikomoniasis koinfeksi terbanyak yakni trikomoniasis + bakterial vaginosis sebesar 3 kasus $(13,64 \%)$, kemudian diikuti dengan trikomoniasis + kandidiasis vulvovaginalis sebesar 2 kasus (9,09\%), sedangkan tanpa infeksi menular seksual lainnya sebesar 15 kasus $(68,18 \%)$.

\section{BAHASAN}

Berdasarkan hasil penelitian di Poliklinik Kulit dan Kelamin RSUP. Prof. Dr. R. D. Kandou Manado Tahun 20112015 (tabel 1) didapatkan 22 kasus baru trikomoniasis $(3,17 \%)$ yang berkunjung di Divisi Infeksi Menular Seksual. Penelitian sebelumnya yang dilakukan di Poliklinik Kulit dan Kelamin RSUP Prof. Dr. R. D. Kandou Manado Tahun 2009-2011 sebesar 7 kasus $(0,81 \%)$ dari 864 kasus IMS. ${ }^{12}$ Menurut data World Heealth Organization, tahun 2008 perkiraan insidensi trikomoniasis sedikit lebih tinggi dibandingkan tahun 2005 yakni 248,5 kasus meningkat menjadi 276,4 kasus $(11,3 \%){ }^{4}$ Hal ini mungkin karena semakin meningkatnya kesadaran masyarakat terhadap kesehatan organ reproduksi, sehingga gejala keputihan membuat masyarakat datang untuk memeriksakan diri. Selain itu kemungkinan karena perubahan gaya hidup masyarakat yang mengarah ke semakin bebasnya dalam berhubungan seksual.

Distribusi kasus berdasarkan umur (tabel 2), kasus Trikomoniasis terbanyak pada kelompok umur 25-44 tahun sebesar 15 kasus $(68,18 \%)$, kedua pada umur 1524 tahun sebanyak 7 kasus $(31,82 \%)$, sedangkan pada umur 45-64 tahun dan $\geq 65$ tahun tidak ditemukan. Penelitian di Amerika Serikat untuk insidensi tahunan diperikirakan 3-5 juta kasus, dan 2 juta diantarnya adalah usia muda (15-24 tahun). ${ }^{13}$ Penelitian lain yang dilakukan di Amerika Serikat diperkirakan trikomoniasis ini mengenai $3,1 \%$ wanita usia reproduksi dan proporsi rentang usia terbesar yakni 20-29 tahun (52,2\%), 30-39 tahun (18,5\%), $<19$ tahun $(16,0 \%)$ dan 40-49 tahun $(9,2 \%) .{ }^{14}$ Umur pasien termuda adalah 16 tahun dan tertua 41 tahun. Hal tersebut sesuai dengan kepustakaan yang menyatakan bahwa trikomoniasis adalah infeksi pada kelamin yang tersering pada wanita aktif seksual, dimana rentang usianya yakni 25-44 tahun yang merupakan rentang seksual aktif. ${ }^{12}$

Distribusi kasus berdasarkan pekerjaannya (tabel 3), profesi Ibu Rumah Tangga sebesar 10 kasus $(45,45 \%)$, pelajar sebanyak 6 kasus $(27,27 \%)$, PNS sebessar 4 kasus $(18,18 \%)$ dan swasta sebesar 2 kasus $(9,10 \%)$. Namun karena data yang ada belum cukup atau tidak spesifik memberikan informasi karena sulit mengevaluasi pekerjaan yang berhubungan dengan resiko terinfeksi trikomoniasis, misalnya pekerjaan ibu rumah tangga tidak digambarkan secara jelas bagaimana perilakunya hingga bisa terjangkit, maupun pekerjaan suaminya yang bisa jadi penularannya berasal dari suaminya yang asimptomatik. Hal ini yang menyebabkan laki-laki bisa menularkannya, tanpa sadar bahwa dia terinfeksi trikomoniasis. Hingga $77,3 \%$ dari infeksi trikomoniasis pada pria 
ialah asimtomatik, hal ini menggambarkan vektor penting untuk transmisi ke perempuan. $^{15}$ Lebih banyak ditemukan pasien yang pekerjaanya sebagai ibu rumah tangga, bukan berarti penyakit ini banyak menyerang perempuan yang berprofesi sebagai ibu rumah tangga, namun kemungkinan hal ini bisa disebabkan karena penularan dari suami yang sering berganti-ganti pasangan. Selain itu kemungkinan lainnya ibu rumah tangga memiliki waktu yang lebih luang untuk memeriksakan diri daripada mereka yang bekerja sebagai PNS dan kebanyakan yang datang berobat pada pagi sampai siang hari sesuai jam kerja di poliklinik sebagian besar berprofesi sebagai ibu rumah tangga, sedangkan wanita yang bekerja ataupun pelajar/mahasiswa mungkin lebih memilih untuk memeriksakan diri ke tempat praktek dokter umum atau spesialis.

Berdasarkan keluhan yang dikeluhkan pasien (Tabel 4), semua pasien mengeluhkan adanya duh tubuh atau keputihan yang keluar dari vagina (100\%), bau amis yang tidak enak dari duh tubuh pasien yakni 59,09\%, keluhan gatal sekitar $36,36 \%$, dispareunia sebanyak $9,09 \%$, dan disuria $4,55 \%$. Sedangkan berdasarkan temuan klinis (tabel 5), yakni didapatkan temuan eritema dinding vagina sebesar $27,27 \%$, temuan klinis berupa duh tubuh kuning berbusa sebesar $18,18 \%$, eritema vulva sebesar $4,55 \%$ dan tidak ditemukan strawberry cervix dari kasus. Strawberry cervix ini patognomonik untuk trikomoniasis, tetapi hanya ditemukan pada 2-3\% pasien hingga jarang bermanfaat untuk diagnosis. ${ }^{16}$ Sesuai dengan teori yang ada bahwa manifestasi klinis dari trikomoniasis bervariasi, diagnosis pasti trikomoniasis adalah dengan menemukan organisme penyebab yang dapat dilihat dengan pemeriksaan basah atau dengan menggunakan mikroskop lapangan gelap. ${ }^{17}$ Menurut kepustakaan Sexually Transmitted Diseases Treatment Guidilnes menyatakan bahwa trikomoniasis sering disertai keluhan duh tubuh vagina yang disertai rasa iritasi atau gatal pada vulva dapat mencapai $23-82 \%$, disertai duh tubuh vagina yang banyak dan berbau sebesar 5075\%. ${ }^{18}$ Penelitian Wolner-Hanssen (1989) dan Rein (1989) menyatakan bahwa hanya $50-75 \%$ penderita mengeluh adanya duh tubuh vagina, sehingga tidak semua wanita dengan trikomoniasis harus selalu disertai duh tubuh vagina. Duh tubuh yang klasik berwarna kuning kehijauan dan berbusa, keadaan ini hanya ditemukan pada 10-30\% penderita. ${ }^{2}$ Keluhan klasik lainnya dapat berupa duh tubuh vagina yang berbau, dispareunia, disuria, dan nyeri perut bagian bawah, belu ada keluhan yang spesifik untuk Trikomoniasis. ${ }^{17,19}$

Berdasarkan ko-infeksi trikomoniasis dengan penyakit menular seksual lainnya (tabel 6) yakni sebesar 7 kasus $(31,82 \%)$, dimana 3 kasus $(13,63 \%)$ ko-infeksi bakterial vaginosis, 2 Kasus $(9,09 \%)$ Kandidiasis Vulvo Vaginalis, 1 kasus (4,54\%) Kondiloma Akuminata, dan 1 kasus ulkus mole $(4,54 \%)$ dalam masa perbaikan. Ada beberapa kemungkinan mekanisme trikomoniasis dapat meningkatkan risiko infeksi menular seksual lainnya yakni trikomoniasis dapat meningkatkan infeksi melalui lesi genital atau perekrutan sel darah putih ke lokasi infeksi, kemudian dapat meningkatkan $\mathrm{pH}$ vagina sehingga mengurangi mekanisme pertahanan terhadap infeksi menular seksual lainnya. ${ }^{20}$ Oleh karena itu pada individu dengan infeksi trikomonas vaginalis perlu dilakukan penapisan terhadap adanya infeksi menular seksual lainnya. ${ }^{19}$

Keseluruhan 22 kasus yang terdiagnosis trikomoniasis seluruhnya dilakukan pemeriksaan laboratorium penunjang berupa sediaan basah dan sediaan gram. Pemeriksaan basah ditemukan parasit Trichomonas vaginalis berbentuk ovoid yang lebih besar dari sel polymorphonuclear (PMN) sehingga semua pasien didiagnosis trikomoniasis. Parasit ini mempunyai lima flagela dimana keempat flagelanya berlokasi di bagian anterior, sedangkan flagel kelima berinkorporasi dengan membrane bergelombang. Pada sediaan basah juga dapat dilihat pergerakan Trichomonas vaginalis. Pemeriksaan mikroskopik untuk menemukan trikomonas 
vaginalis ini menjadi standar untuk mendiagnosis dan kriteria untuk ditatalaksana sebagai trikomoniasis yakni ditemukan parasit trikomonas vaginalis dari sediaan duh tubuh. ${ }^{21}$ Diagnosis terhadap wanita yang terinfeksi trikomonas vaginalis sering dibuat dengan pemeriksaan langsung mikroskopik, dibandingkan pemeriksaan penunjang lainnya karena mempertimbangkan efektifitas biaya. ${ }^{13}$

\section{SIMPULAN}

Berdasarkan hasil penelitian terhadap kasus trikomoniasis di Poliklinik Kulit dan Kelamin RSUP Prof. R. D. Kandou Manado dalam kurun waktu januari 2011 sampai desember 20115: Terdaapat 22 kasus trikomoniasis, paling sering pada kelompok usia 25-44 tahun sebesar 15 kasus $(68,18 \%)$, dengan usia termuda 16 tahun dan usia tertua 41 tahun., pekerjaan terbanyak Ibu Rumah Tangga $(45,45 \%)$, keluhan beragam namun seluruhnya datang dengan keluhan duh tubuh, ko-infeksi IMS lainnya 7 kasus $(31,82 \%)$.

\section{SARAN}

Dalam penelitian ini data catatan yang diberikan di RSUP Prof. R. D. Kandou tidak semuanya lengkap, akhirnya ada beberapa variabel yang perlu dihilangkan menyesuaikan dari data yang terdapat direkam medik pasien. Diharapkan agar bisa memaksimalkan dalam penulisan rekam medik agar lebih lengkap.

Untuk institusi data rekam medik agar dapat memaksimalkan proses penyimpanan data sehingga dapat mempermudah penelitian selanjutnya.

Penelitian ini masih banyak kekurangannya, sehingga bisa dilakukan penelitian selanjutnya dengan menggunakan populasi yang lebih besar

\section{DAFTAR PUSTAKA}

1. Daili SF.Trikomoniasis.Dalam: Djuanda A. llmu penyakit kulit dan kelamin. Jakarta: Balai Penerbit FKUI; 2009. p. 383-384

2. Djajakusumah TS. Trikomoniasis. Dalam: Daili SF, Makes WIB, Zubier F.
Infeksi Menular Seksual. edisi Keempat. Jakarta: Balai Penerbit FKUI; 2009.h.183-192.

3. Susanto L, Adjung SA. Trichomonas vaginalis. Dalam: Sutanto I, Ismid IS, Sjarifuddin PK, Sungkar S. Buku ajar parasitologi kedokteran. edisi keempat. Jakarta: Fakultas Kedokteran Universitas Indonesia; 2008. h.139

4. World Health Organization. Global prevalence and incidence of selected curable sexually transmitted infections: overviews and estimate. WHO/HIV_AIDS/2001.02.Geneva: World Health Organization, 2008.

5. McClelland RS, Sangare L, Hassan WM, Lavroys L, Mandaliya K, Kiarie J, et al. Infection with trichomonas vaginalis increases the risk of HIV-1 acquisition. J Infect Dis. 2007;195:698-702.

6. Silver BJ, Guy RJ, Kaldor JM, Jamil MS, Rumbold AR. Trichomonas vaginalis as a cause of perinatal morbidity: a systematic review and meta-analysis. Sex Transm Dis. 2014;41(6):369-376

7. Somia A.Trikomoniasis. Dalam: Sudoyo AW, Setiyohadi B, Alwi I, Simadibrata M, Setiati S, Syam AF. Buku Ajar Ilmu Penyakit Dalam Jilid Iwende. edisi kelima. Jakarta: Interna Publishing; 2009. p.822-827

8. Jazan $S$, et al.Prevalensi infeksi saluran reproduksi pada wanita penjaja seks di Bitung. Direktorat PPM \& PPL. Jakarta: 2003. h. 16

9. Kissinger P, Secor WE, Leichiter JS, Clark RA, Schmidt N, Curtin E, et al. Early repeated Infections with Trichomoniasis vaginalis among HIV-Positive and HIV- negatife women.CID 2008;46:994-9.

10. Pattullo L, Griffeth S, Ding L, Mortensen J, Reed J, Kahn J, et al. Stepwise Diagnosis of Trichomoniasis vaginalis infection in Adolescent women. J Clin Microbiol 2009; 47(1):39-41.

11. Hobbs MM, Lapple DM, Lawing LF, Schwebke JR, Cohen MS, Swygard $\mathbf{H}$, et al. Methods for detection of trichomonas vaginalis in the male partners of infected women: 
implication for control trichomoniasis. J Clin Microbiol. 2006; 44(11): 3994-99

12. Moeri YE, Suling PL, Pandaleke HEJ. Profil duh tubuh vagina di Poliklinik Kulit dan Kelamin RSUP Prof. DR. R.D. Kandou Manado Tahun 20092011. [Skripsi]. [Manado]: Universitas Sam Ratulangi Manado; 2011. h:670-675

13. Sutton M, Sternberg M, Koumans EH, et al. The prevalence of Trichomonas vaginalis infection among reproductive-age women in the United States, 2001- 2004. Clin Infect Dis 2007;45:1319-26.

14. Meites E, Liata E, Braxton J, Schwebke JR, Bernstein KT, Pathela P, et al. Trichomonas vaginalis in selected US sexually transmitted disease clinics: testing, screening, and prevalence. Sex Transm Dis. November 2013;40(11):1-12

15. Sena AC, Miller WC, Hobbs MM, et al. Trichomonas vaginalis infection in male sexual partners: implications for diagnosis, treatment, and prevention. Clin Infect Dis 2007;44:13-22.
16. Guideline Workowski KA, Berman SM. Sexually transmitted diseases treatment guidelines, 2006. MMWR Recomm Rep. 2006 Aug 4. 55:1-94.

17. Murtiastutik D. Bakterial Vaginosis. Dalam: Barakbah J, Lumintang $\mathrm{H}$, Martodihardjo S, editor. Infeksi menular seksual. Surabaya: AUP; 2008. P.65-71.

18. Center for Diseases Control and Prevention. Sexually transmitted diseases treatment guidelines. MMWR 2010: 58-61.

19. Swygard H, Sena AC, Hobbs MM, Cohen MS. Trichomoniasis: clinical manifestation, diagnosis and management. Sex Transm Infect 2004;80:91-9

20. Allsworth JE, Ratner JA, Peipert JF. Trichomoniasis and other sexually transmitted infections: results from the 2001-2004 National Health and Nutrition Examination Surveys. Sex Transm Dis 2009;36:738-44.

21. Wendel KA, Workowski KA. Trichomoniasis: Challenges to Appropiate Management. CID 2007;44:S123-129. 